\title{
A Novel High-Strength Zn-3Ag-0.5Mg Alloy Processed by Hot Extrusion, Cold Rolling, or High-Pressure Torsion
}

\author{
MARIA WĄTROBA, WIKTOR BEDNARCZYK, JAKUB KAWALKO, \\ SEBASTIAN LECH, KRZYSZTOF WIECZERZAK, TERENCE G. LANGDON, \\ and PIOTR BAŁA
}

\begin{abstract}
A novel $\mathrm{Zn}-3 \mathrm{Ag}-0.5 \mathrm{Mg}$ alloy was plastically deformed using 3 processing paths: hot extrusion (HE), HE followed by cold rolling (CR) and high-pressure torsion (HPT). The processed samples consisted of the $\eta-\mathrm{Zn}$ phase, $\varepsilon-\mathrm{Zn}_{3} \mathrm{Ag}$ precipitates within the matrix, and nanometric $\mathrm{Zn}_{2} \mathrm{Mg}$ precipitates within the $\mathrm{Zn}_{11} \mathrm{Mg}_{2}$ phase located at the grain boundaries. Both the $\eta$ - $\mathrm{Zn}$ phase and $\mathrm{Mg}$-rich phases were enriched in $\mathrm{Ag}$. Electron backscattered diffraction was used to examine the effects of grain size and texture on mechanical behavior with tensile tests performed at room temperature (RT) at different strain rates. The coarse-grained $(\sim 6 \mu \mathrm{m})$ samples after HE exhibited high strength with brittleness due to dislocation interaction with dispersed precipitates and, to some extent, with twinning activation. Significant grain refinement and processing at RT gave an increase in elongation to over 50 pct in CR and 120 pct in HPT. Ductile CR samples with an average grain size of $\sim 2 \mu \mathrm{m}$ and favorable rolling deformation texture gave a yield strength of $\sim 254 \mathrm{MPa}$, a tensile strength of $\sim 456 \mathrm{MPa}$, and a reasonable strain rate sensitivity. These values for the $\mathrm{CR}$ samples meet the mechanical requirements for biodegradable stents in cardiovascular applications.
\end{abstract}

https://doi.org/10.1007/s11661-020-05797-y

(C) The Author(s) 2020

MARIA WAॄTROBA and WIKTOR BEDNARCZYK are with the Faculty of Metals Engineering and Industrial Computer Science, AGH University of Science and Technology, Al. A. Mickiewicza 30, 30-059 Krakow, Poland. Contact e-mail: mwatroba@agh.edu.pl JAKUB KAWAŁKO is with the Academic Centre for Materials and Nanotechnology, AGH University of Science and Technology, Al. A. Mickiewicza 30, 30-059 Krakow, Poland. SEBASTIAN LECH is with the Faculty of Metals Engineering and Industrial Computer Science, AGH University of Science and Technology and also with the International Centre of Electron Microscopy for Materials Science, AGH University of Science and Technology, Al. A. Mickiewicza 30, 30-059 Krakow, Poland. KRZYSZTOF WIECZERZAK is with the Laboratory for Mechanics of Materials and Nanostructures, Empa, Swiss Federal Laboratories for Materials Science and Technology, Feuerwerkerstrasse 39, 3602 Thun, Switzerland. TERENCE G. LANGDON is with the Department of Mechanical Engineering, Materials Research Group, University of Southampton, Southampton SO17 1BJ, UK. PIOTR BAŁA is with the Faculty of Metals Engineering and Industrial Computer Science, AGH University of Science and Technology and also with the Academic Centre for Materials and Nanotechnology, AGH University of Science and Technology.

Manuscript submitted January 13, 2020.

Article published online May 9, 2020

\section{INTRODUCTION}

ContinuOUS medical development and objectives for improving the quality of human lives have created high demands in the field of materials engineering, especially when designing new materials for load-bearing applications. In recent years, zinc and zinc alloys have gained increasing interest as metallic materials in the capacity of short-term biodegradable implants because of their optimal corrosion rate and biocompatibility. However, the use of pure $\mathrm{Zn}$ in the as-cast state for any structural application is not practical due to its inherent brittleness and poor mechanical properties. ${ }^{[1]}$

According to the requirements for cardiovascular applications, ${ }^{[2]}$ the yield strength (YS), ultimate tensile strength (UTS), and elongation to failure $\left(E_{\mathrm{F}}\right)$ should exceed $200 \mathrm{MPa}, 300 \mathrm{MPa}$, and $\sim 18 \mathrm{pct}$, respectively. Furthermore, the minimum value for $E_{\mathrm{F}}$ should be in the range of 30 pct when considering the flexibility that is essential for the expansion of stents in blood vessels. The materials used for stents should exhibit a high UTS/ YS ratio, sufficient ductility, and a high strain hardening rate in order to avoid localized strain concentrations. Additionally, there are other concerns, including the 
high strain rate sensitivity (SRS) of Zn, the susceptibility to creep, and natural aging. ${ }^{[1]}$ Also, time-dependent behavior under a constant load and/or very low strain rates and the possibility of secondary phase precipitation at room temperature (RT) may produce significant microstructural and mechanical properties changes leading to sudden localized damage of the stent.

The low melting temperature of $\mathrm{Zn}\left(T_{\mathrm{m}}=419.5^{\circ} \mathrm{C}\right)$ contributes to its recrystallization temperature of approximately $12^{\circ} \mathrm{C} .^{[3]}$ Therefore, strengthening by plastic deformation is impossible as the deformed grains undergo rapid recovery as well as grain growth at RT. Another strengthening approach is via grain refinement which, as indicated by the Hall-Petch relationship, increases the yield strength and plasticity but only down to a critical grain size. ${ }^{[4-6]}$ The effect of grain refinement strengthening was partially observed in hot extruded $\mathrm{Zn}-\mathrm{Zr},{ }^{[7]} \mathrm{Zn}-\mathrm{Ag},{ }^{[8]} \mathrm{Zn}-\mathrm{Cu}$, ${ }^{[9]} \mathrm{Zn}-\mathrm{Al}$, and $\mathrm{Zn}-\mathrm{Mg}^{[10]}$ alloys. However, in these alloys the mechanical properties may improve because of solid solution strengthening, the presence of second phase precipitates, crystallographic texture, and changing deformation modes which are also considered in the Hall-Petch equation. ${ }^{[11,12]}$

The low solubility of elements in $\mathrm{Zn}$ means that only a few may form solid solutions with $\mathrm{Zn}$ at RT and only at relatively small concentrations. These elements can contribute to grain size reduction and changes in the mechanisms taking place during deformation. ${ }^{[13]} \mathrm{Nev}$ ertheless, solid solution strengthening alone is not sufficient to meet all of the mechanical requirements. Earlier research showed that excessive grain size reduction, below $\sim 3 \mu \mathrm{m}$ in quasi-single phase $\mathrm{Zn}$ alloys after equal-channel angular pressing (ECAP), leads to extreme elongations of more than 600 pct and a significant drop in mechanical strength compared to coarse-grained hot-extruded alloys. ${ }^{[14]}$ In addition, the precipitation of secondary phases strengthens grain boundaries and successfully hinders the recrystallization-induced grain growth occurring during hot deformation. ${ }^{[7-9,15,16]}$

Thus, the fabrication of high-strength ductile $\mathrm{Zn}$ alloys with microstructural stability is challenging, but the approach has been addressed by designing binary and ternary alloys using different castings, additive manufacturing, and other processing techniques. ${ }^{[17,18]}$ In general, the plastic deformation methods used for grain size refinement in $\mathrm{Zn}$ alloys may be divided into three groups: hot deformation, cold deformation, and severe plastic deformation (SPD) processes. The mechanical properties of selected high-strength (YS > $200 \mathrm{MPa}$ and UTS > $300 \mathrm{MPa}$ ) Zn alloys, together with information about their processing methods and applied strain rates during RT tensile tests, are summarized in Table I where these examples are grouped depending on the final processing temperature. These results lead to three main conclusions: (1) $\mathrm{Mg}, \mathrm{Li}$, and $\mathrm{Cu}$ are the most effective alloying elements in strengthening $\mathrm{Zn}$ alloys via grain refinement and precipitation hardening through the formation of $\mathrm{Zn}_{11} \mathrm{Mg}_{2}, \mathrm{Zn}_{2} \mathrm{Mg}, \quad \mathrm{Zn} \mathrm{L}_{4} \mathrm{Li}$ and $\mathrm{Zn}{ }_{4} \mathrm{Cu}$ phases, respectively; (2) the hot processing of $\mathrm{Zn}$ alloys produces materials meeting the strength requirements but often without the required plasticity; (3) cold processing directly after annealing or as a final step of complex processing provides significantly higher ductility in high-strength $\mathrm{Zn}$ alloys.

Except for the brittle $\mathrm{Zn}-1.6 \mathrm{Mg}$ alloy attained after ECAP, other $\mathrm{Zn}$ alloys processed by SPD were not included in Table I because most studies lead to highly ductile but insufficiently strong ultrafine-grained Zn-based materials. ${ }^{[14,30-32]}$

The objective of this research was to examine the characteristics and properties of high-strength, ductile Zn-based materials fabricated by processing using hot, cold, and SPD techniques. Accordingly, a newly designed $\mathrm{Zn}-3 \mathrm{Ag}-0.5 \mathrm{Mg}$ alloy, a potentially biodegradable material for cardiovascular applications, was fabricated and subjected to hot extrusion, hot extrusion followed by cold rolling and high-pressure torsion at RT.

\section{EXPERIMENTAL MATERIAL AND PROCEDURES}

\section{A. Materials Processing}

The $\mathrm{Zn}-3 \mathrm{Ag}-0.5 \mathrm{Mg}$ alloy (wt pct) was fabricated by melting pure zinc (99.995 wt pct), silver (99.995 wt pct), and magnesium (99.95 wt pct) at $650{ }^{\circ} \mathrm{C}$ in a graphite crucible for 30 minutes using an induction furnace, followed by gravity casting into a steel mold. The $\phi 20$ $\mathrm{mm} \times 80 \mathrm{~mm}$ ingot was annealed at $350{ }^{\circ} \mathrm{C}$ for 4 hours to homogenize the microstructure and then watercooled. The precise chemical composition was measured using Energy Dispersive X-ray Spectrometry (EDS) using an FEI VERSA 3D scanning electron microscope (SEM) equipped with an EDAX microanalysis system. The composition was determined based on spectra collected at $20 \mathrm{keV}$ and analyzed by EDAX Genesis software utilizing ZAF correction and averaging several selected areas. The measured weight contents of $\mathrm{Ag}$ and $\mathrm{Mg}$ were $2.99 \pm 0.03$ wt pct and $0.54 \pm 0.04$ wt pct, respectively, which is close to the nominal chemical composition.

The annealed alloy was subjected to three different deformation processes. First, hot extrusion (HE) was performed at $250^{\circ} \mathrm{C}$ with an extrusion speed of $0.1 \mathrm{~mm} /$ $\mathrm{s}$ and an extrusion ratio of 25:1 to obtain $\phi 4 \mathrm{~mm}$ rods. Second, cold rolling (CR) was carried out on the hot-extruded material in a direction parallel to the rod axis to avoid cracking the coarse-grained annealed billet. This process was performed with a thickness reduction up to 75 pct at a constant rolling speed of $0.06 \mathrm{~m} / \mathrm{s}$. Third, high-pressure torsion (HPT) was performed at RT under quasi-constrained conditions ${ }^{[33]}$ with a constant rotation speed of $1 \mathrm{rpm}$. The annealed samples with a diameter of $9.8 \mathrm{~mm}$ and a thickness of $0.85 \mathrm{~mm}$ were processed under an applied pressure of $6.0 \mathrm{GPa}$ through 5 turns to obtain a reasonably homogenous microstructure. 
Table I. Mechanical Properties of Selected High-Strength Zn Alloys

\begin{tabular}{|c|c|c|c|c|c|c|}
\hline $\begin{array}{l}\text { Deformation } \\
\text { Process }\end{array}$ & Composition (Wt Pct) & Strain Rate $\left(\mathrm{s}^{-1}\right)$ & $\begin{array}{c}\mathrm{YS} \\
(\mathrm{MPa})\end{array}$ & $\begin{array}{l}\text { UTS } \\
\text { (MPa) }\end{array}$ & $\begin{array}{l}\text { Elongation } \\
\quad(\mathrm{Pct})\end{array}$ & Reference \\
\hline \multicolumn{7}{|c|}{ Hot Deformation Processes } \\
\hline Hot Rolling & $\mathrm{Zn}-0.2 \mathrm{Li}$ & $1 \times 10^{-3}$ & $245 \pm 7$ & $369 \pm 18$ & $14 \pm 2$ & Zhao et al. ${ }^{[19]}$ \\
\hline & $\mathrm{Zn}-0.4 \mathrm{Li}$ & & $430 \pm 14$ & $448 \pm 2$ & $14 \pm 3$ & \\
\hline & $\mathrm{Zn}-0.7 \mathrm{Li}$ & & $476 \pm 51$ & $468 \pm 4$ & $2.0 \pm 0.3$ & \\
\hline Hot Rolling & $\mathrm{Zn}-0.8 \mathrm{Li}-0.2 \mathrm{Mg}$ & no details & $254 \pm 5$ & $341 \pm 5$ & $31 \pm 6$ & Zhang et al. ${ }^{[20]}$ \\
\hline Hot Extrusion & $\mathrm{Zn}-3 \mathrm{Cu}-1 \mathrm{Mg}$ & $1 \times 10^{-3}$ & 427 & 441 & 0.9 & Tang et al. ${ }^{[21]}$ \\
\hline Hot Extrusion & $\mathrm{Zn}-1.2 \mathrm{Mg}$ & $1 \mathrm{~mm} / \min \left(\sim 3.3 \times 10^{-4 *}\right)$ & $220 \pm 15$ & $363 \pm 5$ & $21 \pm 5$ & Shen et al. ${ }^{[22]}$ \\
\hline $\begin{array}{l}\text { Equal-Channel } \\
\text { Angular }\end{array}$ & $\mathrm{Zn}-1.6 \mathrm{Mg}$ & $1.1 \times 10^{-3}$ & 361 & 423 & 5.2 & Liu et al. ${ }^{[23]}$ \\
\hline Pressing & & & & & & \\
\hline \multicolumn{7}{|c|}{ Cold Deformation Processes } \\
\hline $\begin{array}{l}\text { Hot Extrusion }+ \\
\text { Cold Drawing }\end{array}$ & $\mathrm{Zn}-0.02 \mathrm{Mg}$ & $1 \times 10^{-3}$ & $388 \pm 2$ & $455 \pm 2$ & $5.4 \pm 0.3$ & Wang et al. ${ }^{[24]}$ \\
\hline Hot Extrusion + & $\mathrm{Zn}-0.08 \mathrm{Mg}$ after 0 days & $3.3 \times 10^{-3}$ & 250 & 266 & 30 & Jin et al. ${ }^{[25]}$ \\
\hline \multirow[t]{2}{*}{ Cold Drawing } & $\mathrm{Zn}-0.08 \mathrm{Mg}$ after 1 year & $3.3 \times 10^{-3}$ & $383 \pm 6$ & $434 \pm 6$ & $3.5 \pm 0.5$ & \\
\hline & $\mathrm{Zn}-0.08 \mathrm{Mg}$ after 1 year & $1 \times 10^{-3}$ & 337 & 374 & 34 & \\
\hline $\begin{array}{l}\text { Hot Extrusion }+ \\
\text { Hydrostatic } \\
\text { Extrusion }\end{array}$ & $\mathrm{Zn}-1 \mathrm{Mg}$ & $8 \times 10^{-3}$ & 316 & 435 & 35 & Jarzębska et al. ${ }^{[26]}$ \\
\hline Cold Rolling & $\mathrm{Zn}-0.5 \mathrm{Cu}-0.05 \mathrm{Mg}$ & $2 \times 10^{-3}$ & $241 \pm 5$ & $312 \pm 2$ & $44 \pm 2$ & Ardakani et al. ${ }^{[27]}$ \\
\hline $\begin{array}{l}\text { Hot Rolling + } \\
\text { Cold Rolling }\end{array}$ & $\mathrm{Zn}-4 \mathrm{Cu}$ & $1 \mathrm{~mm} / \mathrm{min}$ & 327 & 393 & 39 & Li et al. ${ }^{[28]}$ \\
\hline $\begin{array}{l}\text { Hot-Warm (100 } \\
\left.{ }^{\circ} \mathrm{C}\right) \text { Rolling }\end{array}$ & $\mathrm{Zn}-0.8 \mathrm{Li}$ & $3.3 \times 10^{-4}$ & 261 & 401 & 80 & Li et al. ${ }^{[29]}$ \\
\hline
\end{tabular}

*Assuming 5-fold specimens according to preparation mentioned in paper based on ASTM E8/E8M-11 standard method.

\section{B. Microstructural Characterization}

Microstructural observations of samples in the as-cast, annealed, HE, CR, and HPT states were performed using an SEM equipped with EDS and EDAX Electron Back-Scattered Diffraction (EBSD) detectors. All samples were prepared by grinding with SiC papers to \#2000 grit and polishing using 3 and $1 \mu \mathrm{m}$ water-free diamond suspensions. To remove the residual scratches and deformed layer, low-angle $\mathrm{Ar}^{+}$ion polishing was performed at $2.5 \mathrm{kV}$ for 45 minutes. The observations of the as-cast and annealed samples were performed on the cross-sections and the plastically deformed samples were examined on longitudinal sections. Schematic illustrations of the alloy processing routes and the sample preparation are given in Figure 1.

Lamellae from the extruded $\mathrm{Zn}-3 \mathrm{Ag}-0.5 \mathrm{Mg}$ alloy were prepared using an FEI Quanta 3D 200i SEM equipped with a focused ion beam (FIB) facility and analyzed using an FEI Tecnai TF 20 X-TWIN transmission electron microscope (TEM). For phase identification, EDS data were combined with selected area electron diffraction (SAED) patterns and then analyzed utilizing JEMS software. The EDAX EBSD system and TSL OIM ${ }^{\mathrm{TM}}$ software were used to acquire and analyze the crystallographic orientation maps. In order to obtain an optimal number of grains for further analysis, EBSD maps of either $120 \times 120 \mu \mathrm{m}^{2}$ or $15 \times 15 \mu \mathrm{m}^{2}$ were acquired with step sizes of either $150 \mathrm{~nm}$ (HE, CR) or 30 nm (HPT), respectively.
The average grain size, crystallographic orientation maps, texture, and grain boundary misorientation distributions were analyzed using the MTEX toolbox in Matlab $^{\text {TM }}$. A single grain was defined as a set of at least 5 points with a misorientation angle between neighboring grains higher than $15 \mathrm{deg}$. The misorientation angle for subgrains was set within the range of 3 to $15 \mathrm{deg}$. Only grains of the $\mathrm{Zn}$-based matrix were considered and the precipitates of other phases were excluded from the analysis. Additionally, the phase composition was examined using a Panalytical Empyrean X-ray diffractometer with $\mathrm{CuK} \alpha$ radiation $(\lambda=1.54 \AA)$. Diffractograms were collected in the 20 to $90 \mathrm{deg}$ range of $2 \theta$ angles at $40 \mathrm{kV}, 40 \mathrm{~mA}$, with a scanning rate of $0.4 \mathrm{deg} /$ min and a step size of $0.02 \mathrm{deg}$. The XRD patterns were analyzed using TOPAS ${ }^{[34]}$ software and Rietveld analysis. $^{[35]}$

\section{Mechanical Properties Testing}

Tensile tests for materials after HE, CR, or HPT were conducted at RT using an Instron 5966 universal testing machine with initial strain rates of $10^{-4}, 10^{-3}$, and $10^{-2}$ $\mathrm{s}^{-1}$. Tensile specimens were machined from the extruded rods in $\mathrm{HE}$ to obtain gauge lengths and diameters equal to 30 and $3 \mathrm{~mm}$, respectively. Wire electro-discharge machining was used to cut dog-bone type flat specimens with gauge sections of about $16 \times 2 \times 1 \mathrm{~mm}^{3}$ along the rolling direction after $\mathrm{CR}$ and also to cut 


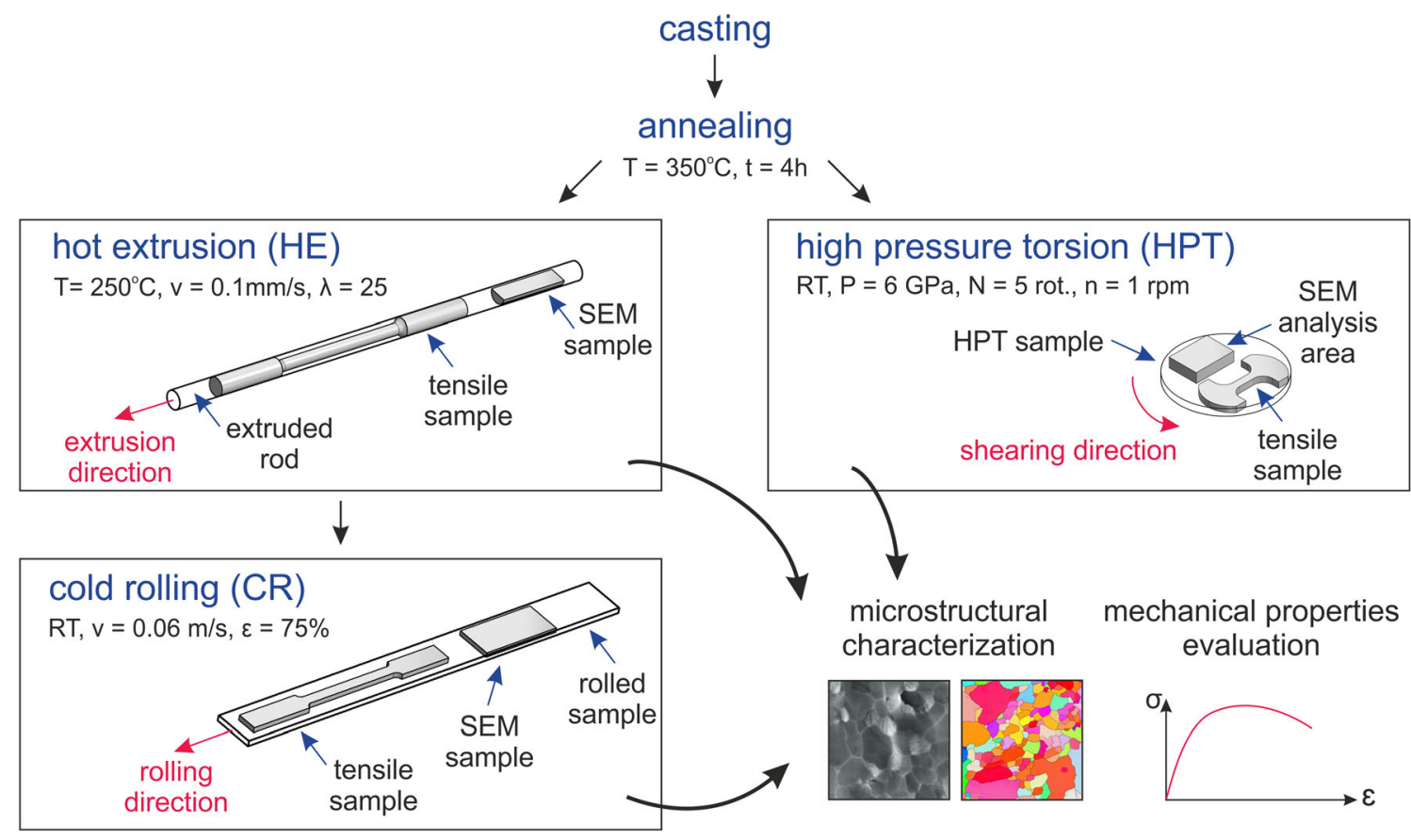

Fig. 1-Schematic of processing routes of the $\mathrm{Zn}-3 \mathrm{Ag}-0.5 \mathrm{Mg}$ alloy showing sections used for SEM-EBSD analysis and geometry of tensile samples. Note that the scale in the sample drawings was not preserved.

micro-specimens after HPT with $1.5 \mathrm{~mm}$ gauge lengths and gauge sections of $0.6 \times 0.7 \mathrm{~mm}^{2}$. Based on the recorded force-displacement curves and equipment specifications, the measurement uncertainties were calculated for the measured yield stress, ultimate tensile stress, and elongation to failure. ${ }^{[36]}$

\section{EXPERIMENTAL RESULTS}

\section{A. Microstructure of the Initial Material}

In Figure 2, the microstructures and elemental information for the $\mathrm{Zn}-3 \mathrm{Ag}-0.5 \mathrm{Mg}$ alloy are shown for (a, c, e) the as-cast and $(b, d, f)$ the annealed states. After casting, the material exhibits a dendritic morphology with a characteristic lamellar eutectic mixture in the interdendritic regions. The SEM-EDS elemental mapping in Figure 2(c) confirms the presence of $\mathrm{Ag}$ within the dendrites, probably existing as a dissolved element in $\mathrm{Zn}$, and there is an increased concentration of $\mathrm{Mg}$ within the interdendritic regions. The main peaks on the $\mathrm{X}$-ray diffractogram in Figure 2(e) originate from the $\eta$ - Zn matrix phase. According to binary phase diagrams, ${ }^{[37]}$ the maximum solubility of $\mathrm{Ag}$ and $\mathrm{Mg}$ in liquid $\mathrm{Zn}$ is 3 and $0.1 \mathrm{pct}$, respectively. It was observed during Rietveld analysis that peaks related to $\eta-\mathrm{Zn}$ exhibit slightly different positions and the c/a ratio of the $\eta$ - $\mathrm{Zn}$ in the alloy is different by comparison with pure $\mathrm{Zn} \cdot{ }^{[38]}$ Thus, dissolved $\mathrm{Ag}$ atoms decrease the interplanar distance in the $\mathrm{Zn}$ crystal cell in the c-axis and generally lead to an increase in the c/a ratio of the $\eta-\mathrm{Zn}$ phase with increasing amounts of $\mathrm{Ag} .{ }^{[39]}$ This suggests the presence of $\mathrm{Ag}$ and most likely small amounts of $\mathrm{Mg}$ in the $\eta-\mathrm{Zn}$ solid solution. A few peaks of relatively low intensity and the broadening of some peaks belonging to the $\eta$ - $\mathrm{Zn}$ phase suggest the presence of a small fraction of secondary phases in the alloy. During indexing of the diffraction peaks, all possible phases in the $\mathrm{Zn}-\mathrm{Ag}$ and $\mathrm{Zn}-\mathrm{Mg}$ systems were considered and it was found that secondary phases in the alloy correspond to $\mathrm{Zn}_{2} \mathrm{Mg}$ and probably $\varepsilon-\mathrm{Zn}_{3} \mathrm{Ag}$. The $\mathrm{Zn}_{2} \mathrm{Mg}$ phase, together with the $\eta-\mathrm{Zn}$ phase, is a constituent of the eutectic mixture observed in the interdendritic regions.

After annealing, the dendritic structure was transformed into large equiaxed grains and it is apparent from the SEM-EDS elemental maps in Figure 2(d) that $\mathrm{Ag}$ is more uniformly distributed within the sample. According to the $\mathrm{Zn}-\mathrm{Ag}$ phase diagram for a concentration of 3 pct Ag, ${ }^{[37]}$ after rapid water cooling from $350{ }^{\circ} \mathrm{C} \mathrm{Ag}$ forms a supersaturated solid solution with $\mathrm{Zn}$ of the $\eta-Z n$ phase. In place of the lamellar eutectic mixture, coagulated grains of $\mathrm{Mg}$-rich second phase form along the primary dendritic boundaries. In addition, the EDS point analyses marked with yellow crosses in Figure 2(d) indicate that the average atomic concentrations of $\mathrm{Mg}, \mathrm{Ag}$, and $\mathrm{Zn}$ in these grains are about 15 pct, 3 pct, and 82 pct, respectively. The corresponding X-ray diffractogram in Figure 2(f) supports a phase transformation from a $\eta-\mathrm{Zn}+\mathrm{Zn}_{2} \mathrm{Mg}$ eutectic mixture to a $\mathrm{Zn}_{11} \mathrm{Mg}_{2}$ phase enriched in $\mathrm{Ag}$. It should be noted that the possibility of a small fraction of $\varepsilon-\mathrm{Zn}_{3} \mathrm{Ag}$ phase in the microstructure in the annealed state cannot be excluded. 

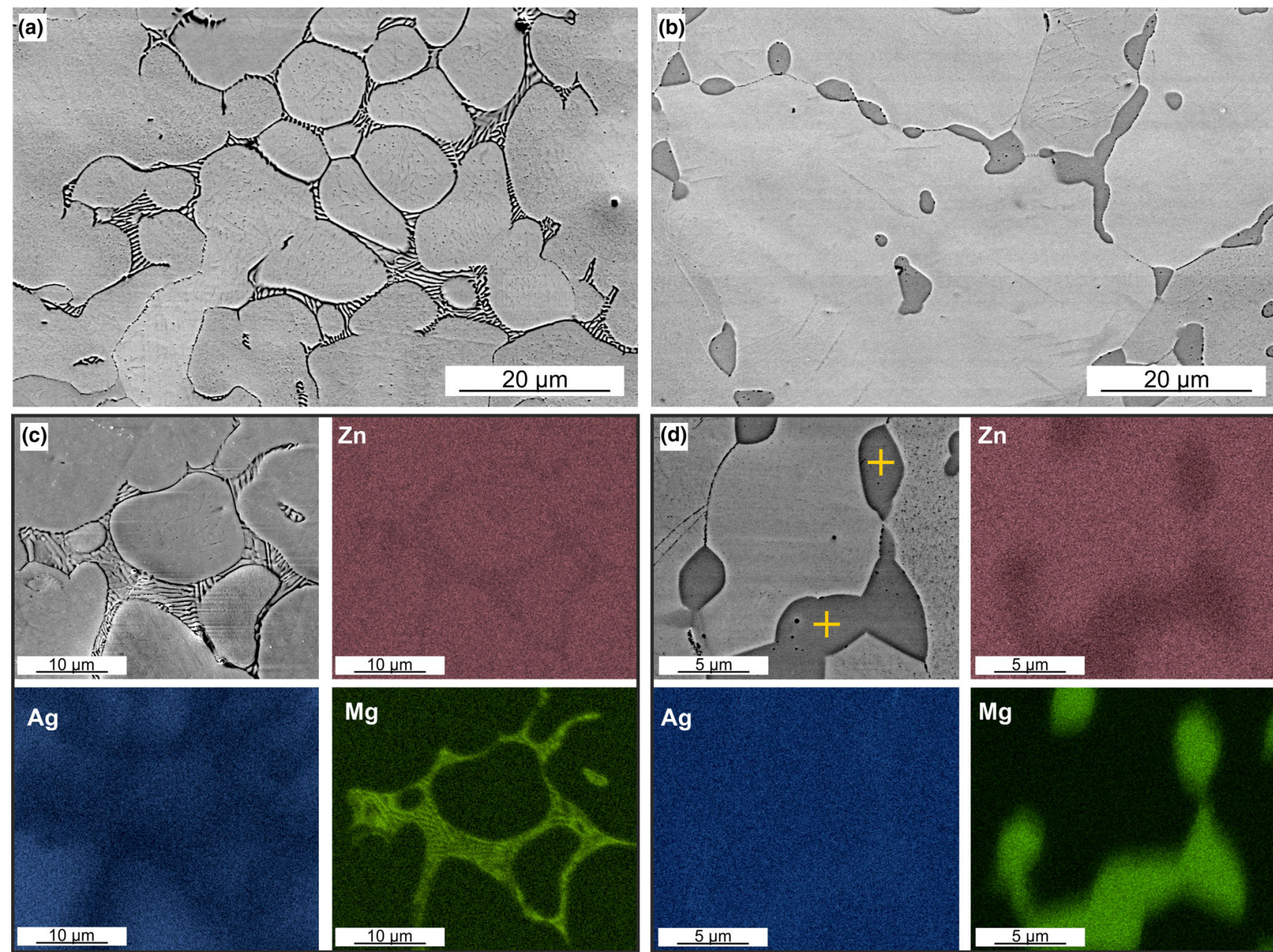

(e)

(f)
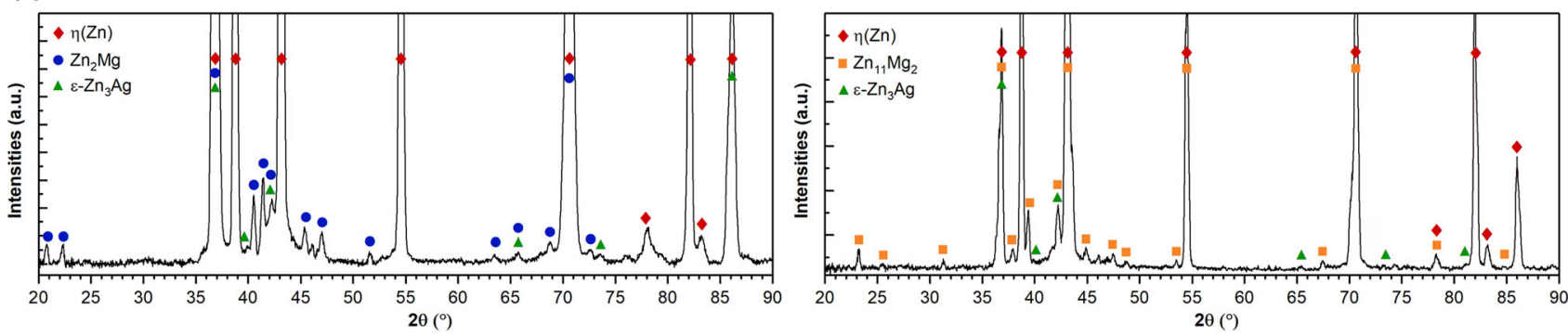

Fig. 2-Microstructures $(a),(b)$, EDS elemental maps $(c),(d)$, and X-ray diffractograms $(e),(f)$ of the as-cast $((a),(c),(e))$ and annealed ((b), (d), (f)) $\mathrm{Zn}-3 \mathrm{Ag}-0.5 \mathrm{Mg}$ alloy.

\section{B. Microstructures After Plastic Deformation Processes}

The microstructures of the annealed material after processing through the three different deformation processes are shown in Figure 3 where $(a, d)$ is for $\mathrm{HE},(b, e)$ is for CR, and (c, f) is for HPT. It can be seen in Figures 3((d) to (f)) that the grain size is significantly refined for all three processing routes. Similar to the annealed state, the bright grains of the $\eta$ - $\mathrm{Zn}$ matrix phase are located mostly at the grain boundaries, whereas the grains of the Mg-rich phase marked with red arrows remain in the microstructure. Additionally, precipitates of another intermetallic phase marked with yellow arrows are visible in the form of small white particles. It is reasonable to assume that the presence of precipitates hinders grain growth after dynamic recrystallization, most probably during the processing, together with the breaking of the Mg-rich grains under the applied external stress.

The Mg-rich grains are visible as white grains in Figures 3((a) to (c)) as observed using the secondary electron mode in the SEM and these grains are distributed vertically in the $\mathrm{HE}$ and $\mathrm{CR}$ samples corresponding to the extrusion (ED) and rolling (RD) directions, respectively. It appears that other small precipitates are more randomly dispersed both at grain boundaries and within the $\eta-\mathrm{Zn}$ grains. For the HPT 

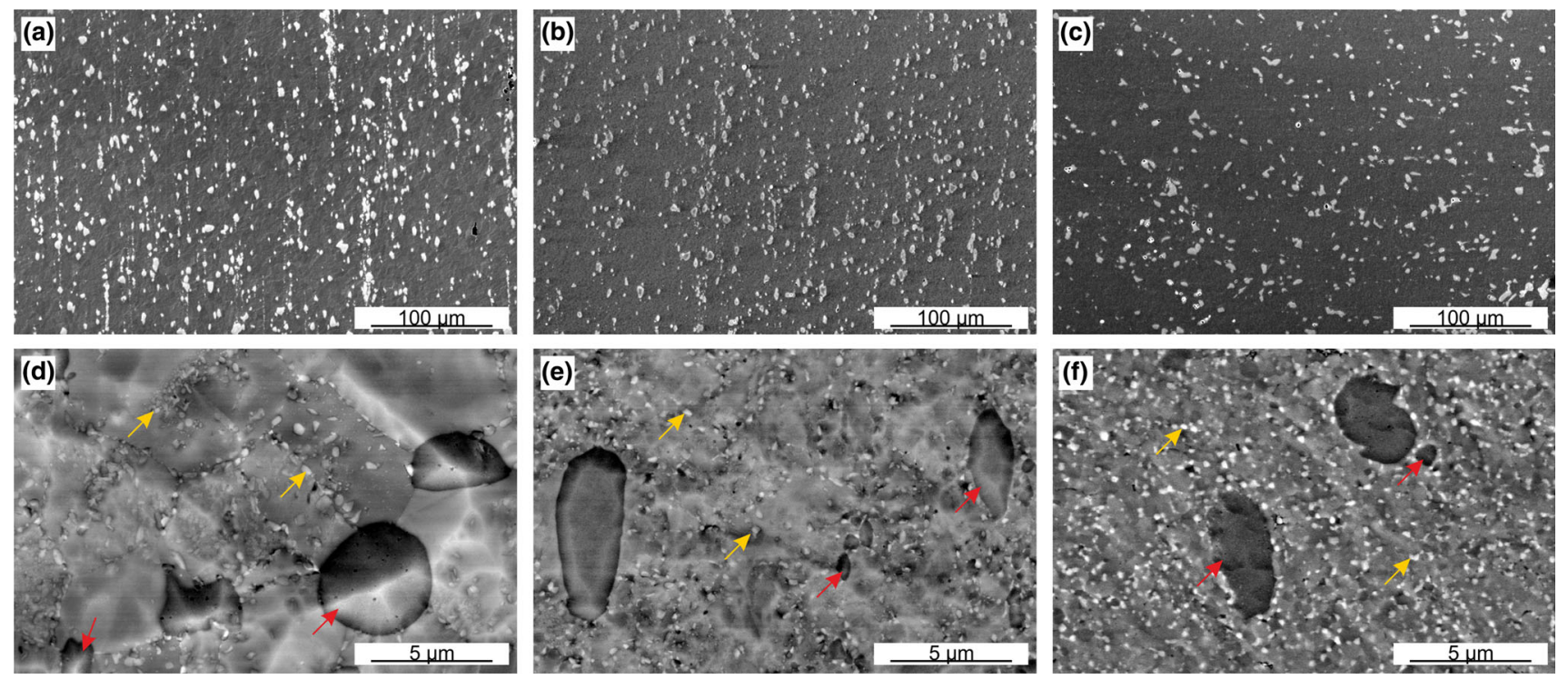

Fig. 3-Microstructures of the hot extruded $(a),(d)$, cold rolled $(b),(e)$ and HPT $(c),(f)$ Zn-3Ag-0.5Mg alloy: SEM-SE (a) to (c), SEM-BSE (d) to (f). Yellow and red arrows indicate the newly precipitated phase and $\mathrm{Mg}$-rich phase, respectively.

sample shown in Figure 3(c), all precipitates are distributed uniformly within the $\eta-\mathrm{Zn}$ matrix. The volume fractions of this Mg-rich phase were estimated as 10.8, 10.4 , and 8.8 pct for HE, CR, and HPT, respectively, where this is consistent with the volume fraction determined for the annealed state which was equal to 10.1 pct. The slight differences in the topology of the samples shown in Figures 3((d) to (f)) are due to variations arising from the metallographic preparation process.

Based on the $\mathrm{Zn}-\mathrm{Ag}$ and $\mathrm{Zn}-\mathrm{Mg}$ phase diagrams, ${ }^{[37]}$ no phase transformations are expected below the highest temperature of $250{ }^{\circ} \mathrm{C}$ applied during processing. Therefore, an XRD analysis was performed to identify the phases present in the HE sample. The XRD diffractogram of the HE sample in Figure 4 confirms the presence of $\eta-\mathrm{Zn}, \mathrm{Zn}_{11} \mathrm{Mg}_{2}$, and $\varepsilon-\mathrm{Zn}_{3} \mathrm{Ag}$ phases in the microstructure but additional peaks of other intermetallic phases were not detected probably due to texturing after extrusion and their small volume fractions. Therefore, SEM-EDS and TEM analyses were performed and Figure 5(a) shows the SEM-SE image of the extruded sample with the corresponding SEM-EDS elemental distribution maps. As in the annealed state, $\mathrm{Mg}$ occurs mainly in the larger grains composed of the $\mathrm{Zn}_{11} \mathrm{Mg}_{2}$ phase and the small precipitates are enriched in Ag.

Phase identification of these small precipitates was performed based on TEM observations and SAED patterns shown in Figure 5((b) and (c)). It can be seen in Figure 5(b) that the micrometric Mg-rich grains are composed of nanosized particles which are much smaller than $100 \mathrm{~nm}$. The SAED pattern indicates a mixture of the $\mathrm{Zn}_{11} \mathrm{Mg}_{2}$ phase and fine precipitates of the $\mathrm{Zn}_{2} \mathrm{Mg}$ phase where these phases are identified based on spot and ring diffraction patterns, respectively. Using STEM-EDS analysis performed on a few points marked with red crosses in Figure 5(b), the average chemical composition (at. pct) was close to 87 pet $\mathrm{Zn}, 3$ pct $\mathrm{Ag}$,

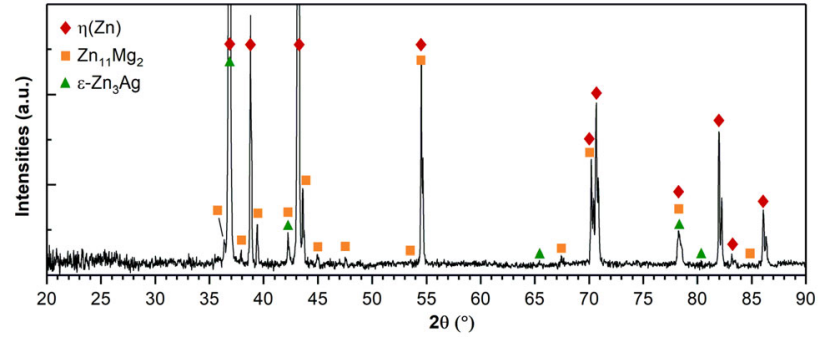

Fig. 4-X-ray diffractogram of the hot extruded $\mathrm{Zn}-3 \mathrm{Ag}-0.5 \mathrm{Mg}$ alloy.

and $10 \mathrm{pct} \mathrm{Mg}$, thereby suggesting that $\mathrm{Ag}$ occurs in the $\mathrm{Mg}$-rich regions so that these phases are more complex with partial substitution of Ag. In addition, it was confirmed that the small precipitates observed within the $\eta$ - Zn grains and at grain boundaries do not contain $\mathrm{Mg}$ and belong instead to the $\varepsilon-\mathrm{Zn}_{3} \mathrm{Ag}$ phase. The average atomic concentrations of the points marked with yellow crosses in Figure 5(c) were approximately 82 pct $\mathrm{Zn}$ and 18 pct $\mathrm{Ag}$ and the average size of the $\varepsilon-\mathrm{Zn}_{3} \mathrm{Ag}$ precipitates was measured within the range of a few dozen to a few hundred nm.

\section{SEM-EBSD Analysis}

Measurements by EBSD were used to examine the grain size and grain orientations after processing. Figure 6 shows EBSD-IPF orientation maps and misorientation angle distributions of samples after $(\mathrm{a}, \mathrm{d}) \mathrm{HE},(\mathrm{b}, \mathrm{e}) \mathrm{CR}$ and $(\mathrm{c}, \mathrm{f}) \mathrm{HPT}$. All three conditions show grain refinement compared with the annealed state and Table II summarizes the average grain sizes and the densities of high-angle (HAGB) and low-angle (LAGB) grain boundaries. The largest grain size was $6.0 \pm 2.5$ $\mu \mathrm{m}$ after $\mathrm{HE}$ but this was reduced to $1.8 \pm 1.4 \mu \mathrm{m}$ by CR and then to $1.2 \pm 1.1 \mu \mathrm{m}$ after HPT. Subgrains visible in 

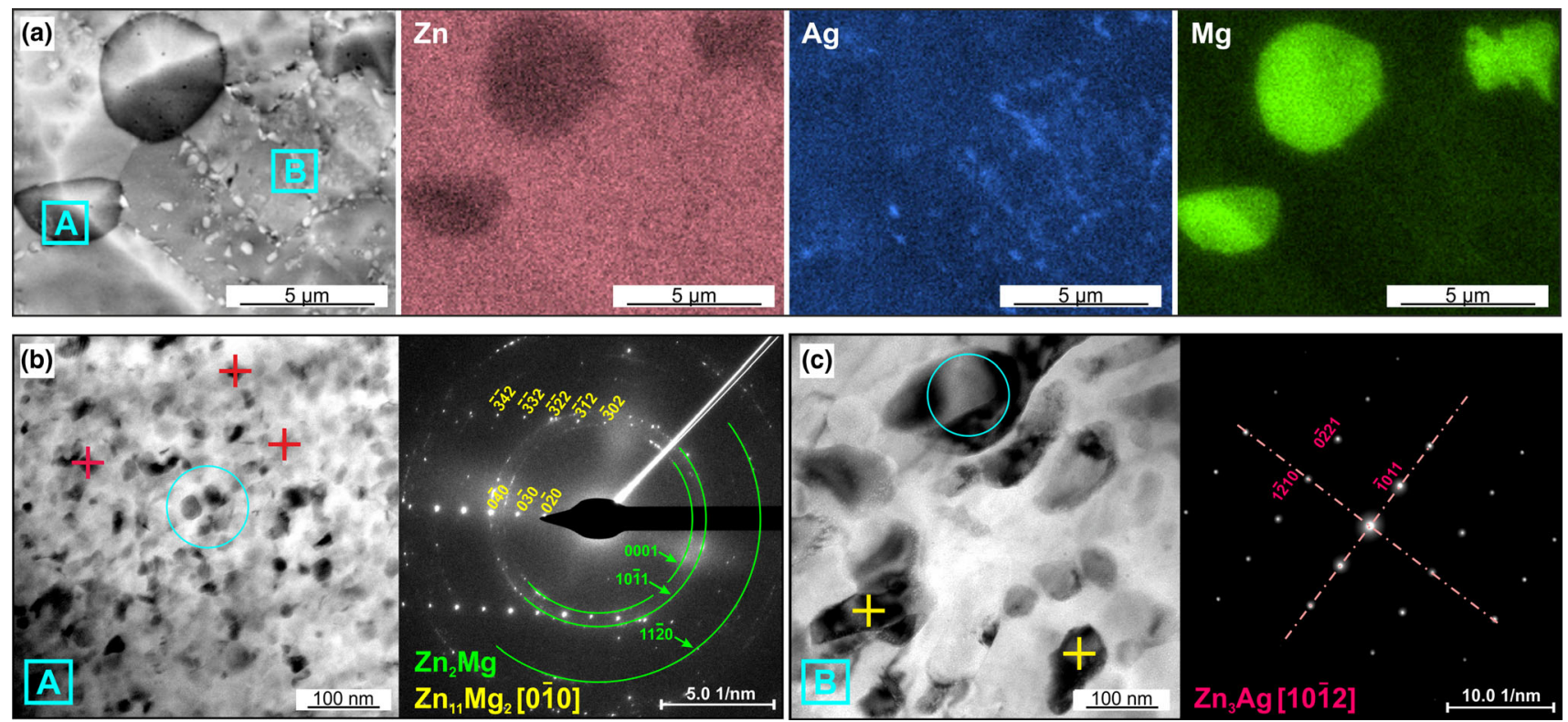

Fig. 5-SEM-BSE image and SEM-EDS elemental maps for element distributions in the investigated areas of extruded $\mathrm{Zn}-3 \mathrm{Ag}-0.5 \mathrm{Mg}$ alloy $(a)$, SEM. TEM bright-field images and SAED patterns corresponding to Mg-rich grains similar to the area [A] (b) and Ag-rich precipitates similar to the area $[\mathrm{B}](c)$ marked in (a).

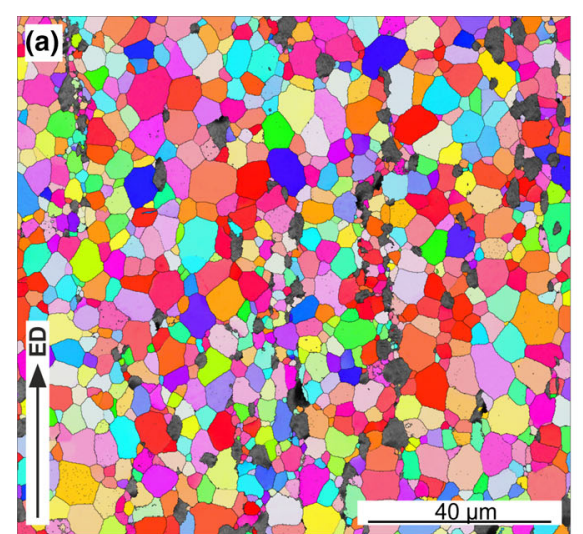

(d)

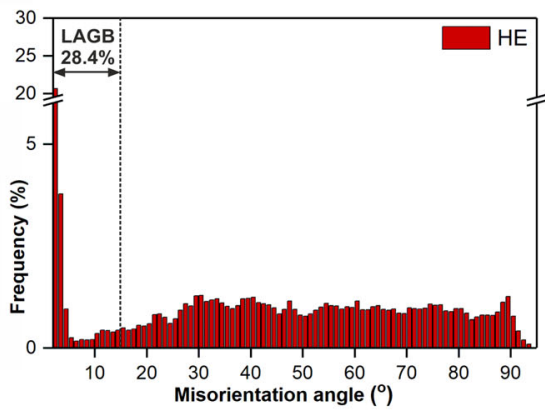

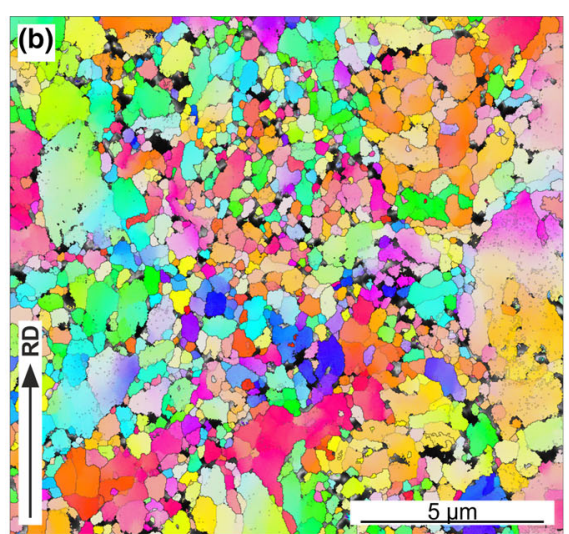

(e)

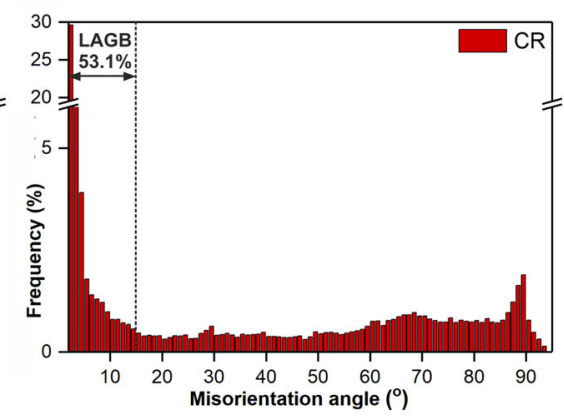

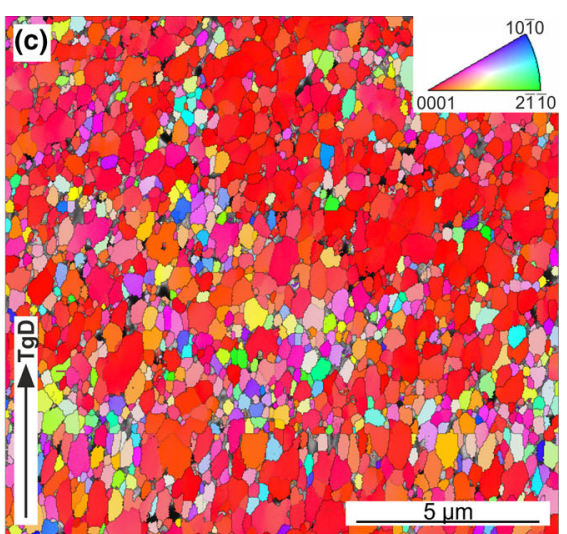

(f)

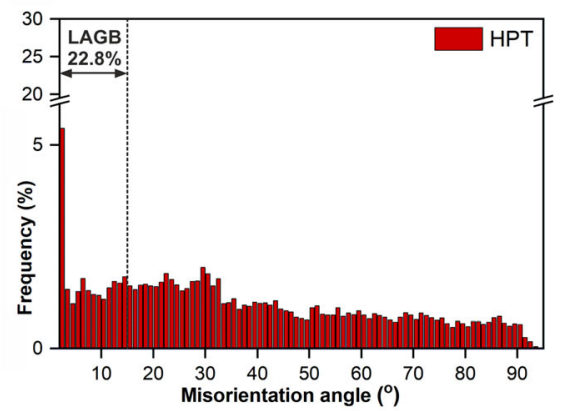

Fig. 6-EBSD-IPF orientation maps $(a)$ to $(c)$ and distribution of grain boundary misorientation angles $(d)$ to $(f)$ for $\mathrm{Zn}-3 \mathrm{Ag}-0.5 \mathrm{Mg}$ alloy after HE ((a), (d)), CR ((b), (e)) and HPT ((c), (f)). Please pay attention to different scale bars in maps (a) to (c). ED, extrusion direction; $R D$, rolling direction; $T g D$ tangential direction.

the CR and HPT samples were about one-half of the grain size. Most grains were oriented in [0001] directions after HPT but they were more randomly oriented after $\mathrm{HE}$ and $\mathrm{CR}$.
The grain boundary misorientation angle distributions are plotted in Figure 6((d) to (f)) and in the CR sample a peak is visible at $\sim 87 \pm 3$ deg related to the presence of twin boundaries. These distributions are 
consistent with the calculated densities of HAGBs and LAGBs in Table II. The density of LAGBs relates to the subgrain structure and increases significantly after CR. By contrast, the highest density of HAGBs occurs in the HPT sample, which is typical for SPD processing. ${ }^{[40]}$

\section{Texture Analysis}

Crystallographic texture analysis was performed based on (0002), (10 $\overline{1} 0)$ and $(11 \overline{2} 0)$ pole figures recalculated from the EBSD data. These data were measured on sample planes parallel to ED, RD and the shearing plane in the HE, CR, and HPT samples, respectively, as presented in Figure 1. Figure 7 shows the characteristic textures typical for anisotropic hexagonal close-packed (HCP) metals after (a) HE, (b) CR, and (c) HPT.

The HE sample exhibits a (1010) fiber texture with the $(0002)$ and $(11 \overline{2} 0)$ poles more randomly distributed and with a texture that is axially symmetric. The lowest maximum intensities were recorded in this case. This texture is usually a result of the activation of basal slip systems during extrusion as is typical for HCP metals while the prismatic planes are perpendicular to the ED. ${ }^{[41,42]}$

In the texture for the CR sample, the maximum intensity of the (0002) pole figure is split into two maxima and tilted towards the RD. Typically, for rolled pure $\mathrm{Zn}$, the $(11 \overline{2} 0)$ pole aligns with the RD and the (1010) pole is parallel to the transverse direction (TD). For the $\mathrm{Zn}-3 \mathrm{Ag}-0.5 \mathrm{Mg}$ alloy, the maxima are slightly shifted which is probably related to the presence of deformed grains. Such texturing originates from a combination of basal slip and large-scale twinning ${ }^{[43]}$ and this is consistent with the peak observed in Figure 6(e) corresponding to the existence of twin boundaries.

By contrast, the high shear stress in HPT leads to a strong basal texture with the highest maximum intensity of 24 and with many grains with a parallel c-axis. The six maxima visible in the prismatic pole figures with a maximum intensity of 6 relates to the 6-fold symmetry of HCP crystals and the preferred orientations achieved by the crystals during torsional straining in terms of the tangential monotonic shearing direction (TgD). Similar results were reported for $\mathrm{Zn}-\mathrm{Mg}$ hybrids after 5 turns during HPT where there was no prismatic texture and the alignment of $(10 \overline{1} 0)$ and $(11 \overline{2} 0)$ with the radial direction $(\mathrm{RdD})$ was in agreement with the development of a basal texture. ${ }^{[4]}$ Generally, the observed textures of HPT samples are composed of two constituents corresponding to basal and $(0001)[11 \overline{2} 0]$ textures. ${ }^{[45]}$

\section{E. Mechanical Properties}

Uniaxial tensile tests were conducted to examine the effect of each processing technique on the mechanical properties. Tensile tests were performed at three different strain rates and the results are depicted in Figures 8((a) to (c)) as engineering stress vs engineering strain for the HE, CR, and HPT samples, respectively. To highlight the differences in mechanical properties after the various processing routes, all results are summarized in Table III.

For the HE samples, the YS and UTS values increase consistently with increasing strain rate but there is no systematic change in the elongations to failure. At the microscopic level, a brittle mode was confirmed during fractographic analysis as shown in Figure 8(d) where the fracture surface has small cleavage facets (marked with white arrows) indicating transgranular fracture through the $\mathrm{Zn}$-based grains.

The application of CR after hot extrusion leads to higher values of the UTS but the values of the YS are lower than in the HE condition. This is caused by the grain size refinement and by the texture present after extrusion, which is more susceptible to tensile deformation. A transformation from brittle to ductile fracture mode was recorded after $\mathrm{CR}$ as shown in Figure 8(e) where the fracture surface has numerous spherical dimples and some tearing edges that are consistent with the observed necking and total elongations to failure above 30 pct.

The ultrafine-grained sample after HPT gave the highest UTS of $\sim 516 \mathrm{MPa}$ when straining at $10^{-2} \mathrm{~s}^{-1}$ but the values for the UTS at the two lower strain rates were lower than for the CR condition. The most significant differences were recorded for the total elongations in the HPT samples which were much higher than for the CR samples at all three strain rates. Necking was observed at all strain rates and Figure 8(f) shows an example of small spherical and slit-like dimples on the fracture surface. These dimples are significantly deeper than in the rolled state and the elongation to failure was double the value for the CR state. In ductile fracture modes, the $\varepsilon-\mathrm{Zn}_{3} \mathrm{Ag}$ phase precipitates and $\mathrm{Mg}$-rich grains are not responsible for initiating cracks and it appears that other deformation mechanisms, such as grain boundary sliding (GBS), ${ }^{[14]}$ may be responsible for the high ductility in the fine-grained samples.

\section{DISCUSSION}

\section{A. Effect of Simultaneous Additions of Silver and Magnesium on the Initial Microstructure}

Microstructural investigations reveal that the simultaneous addition of $\mathrm{Ag}$ and $\mathrm{Mg}$ to pure $\mathrm{Zn}$ leads to a multi-phase microstructure in the $\mathrm{Zn}-3 \mathrm{Ag}-0.5 \mathrm{Mg}$ alloy. According to the $\mathrm{Zn}-\mathrm{Mg}$ and $\mathrm{Zn}-\mathrm{Ag}$ phase diagrams, ${ }^{[37]}$ the phases that may appear in equilibrium conditions at RT are the $\eta$ - Zn solid solution enriched with Ag, $\varepsilon-\mathrm{Zn}_{3} \mathrm{Ag}$, and $\mathrm{Zn}_{11} \mathrm{Mg}_{2}$. Nevertheless, it is noted that in the ternary $\mathrm{Zn}-\mathrm{Mg}-\mathrm{Ag}$ system a substitution of $\mathrm{Zn}$ and/ or $\mathrm{Ag}$ sites in the $\varepsilon-\mathrm{Zn}_{3} \mathrm{Ag}$ phase with $\mathrm{Mg}$ atoms and $\mathrm{Zn}$ and/or $\mathrm{Mg}$ sites in the $\mathrm{Zn}_{11} \mathrm{Mg}_{2}$ phase with $\mathrm{Ag}$ atoms may be a possibility. During crystallization, the alloy undergoes a peritectic reaction $\left(\mathrm{L}+\varepsilon-\mathrm{Zn}_{3} \mathrm{Ag} \rightarrow \eta\right.$ - $\left.\mathrm{Zn}\right)$ in which the primary $\varepsilon-\mathrm{Zn}_{3} \mathrm{Ag}$ phase is formed. As a result of this reaction together with liquid, there is a partial formation of a $\eta$ - $\mathrm{Zn}$ solid solution. 
Table II. Average Grain and Subgrain Size, and Density of HAGB and LAGB After HE, CR, and HPT

\begin{tabular}{lcccc}
\hline Material & Grain Size $(\mu \mathrm{m})$ & Subgrain Size $(\mu \mathrm{m})$ & Density of HAGB $\left(\mu \mathrm{m} / \mu \mathrm{m}^{2}\right)$ & Density of LAGB $\left(\mu \mathrm{m} / \mu \mathrm{m}^{2}\right)$ \\
\hline HE & $6.0 \pm 2.5$ & $5.5 \pm 2.1$ & 0.57 & 0.21 \\
CR & $1.8 \pm 1.4$ & $1.0 \pm 0.9$ & 3.81 & 5.75 \\
HPT & $1.2 \pm 1.1$ & $0.6 \pm 0.3$ & 5.46 & 1.61 \\
\hline
\end{tabular}

(a)
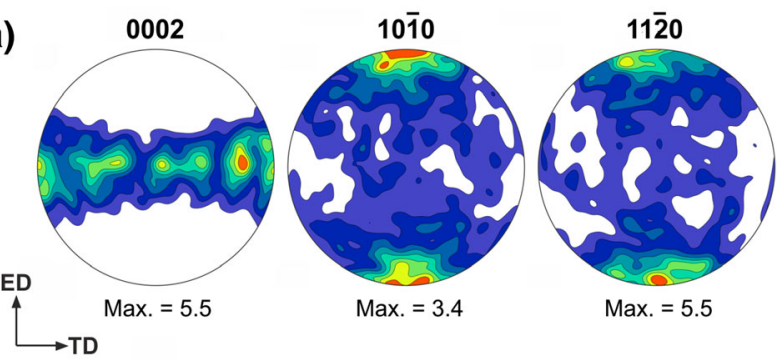

(b)
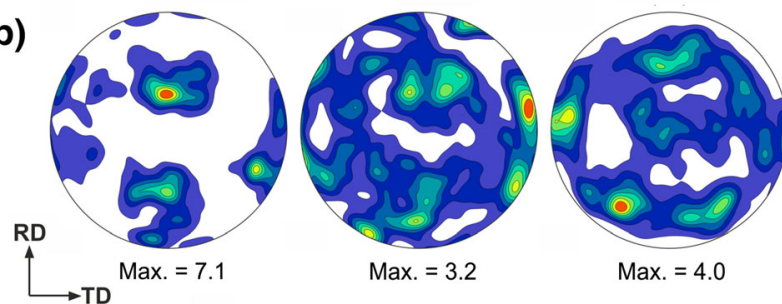

(c)

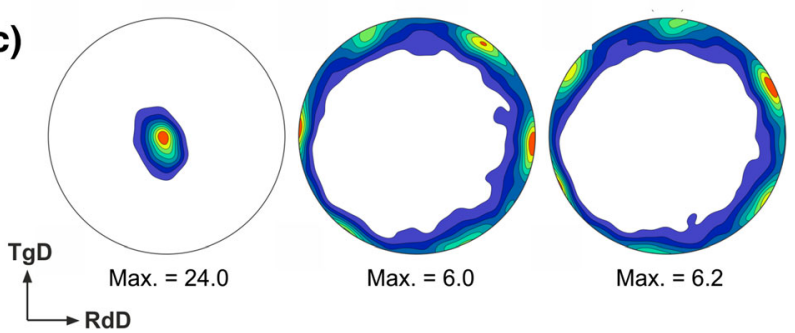

Fig. 7-Basal (0002), and prismatic $(10 \overline{1} 0),(11 \overline{2} 0)$ pole figures of HE $(a)$, CR $(b)$, and HPT $(c)$ samples.

Some local heterogeneities and non-uniform distributions within the $\eta$ - Zn phase may appear at 3 pct $\mathrm{Ag}$ leading to further precipitation of the $\varepsilon-\mathrm{Zn}_{3} \mathrm{Ag}$ phase with decreasing temperature and, as the temperature drops below $364{ }^{\circ} \mathrm{C}$, the remaining $\mathrm{Mg}$-rich liquid undergoes a eutectic reaction. As documented for $\mathrm{Zn}-0.5 \mathrm{Mg}$ alloy, ${ }^{[46]}$ two kinds of competitive eutectic mixtures, of the form $\mathrm{Zn}+\mathrm{Zn}_{11} \mathrm{Mg}_{2}$ and $\mathrm{Zn}+\mathrm{Zn}_{2} \mathrm{Mg}$, can appear. It was also shown that, due to non-equilibrium solidification, the $\mathrm{MgZn}_{2}$ phase appears in the $\mathrm{Zn}-1.8$ pet $\mathrm{Mg}$ alloy. ${ }^{[47]}$ Based on the XRD diffractogram in Figure 2(e), the $\eta-\mathrm{Zn}+\mathrm{Zn}_{2} \mathrm{Mg}$ eutectic mixture formed in the as-cast state and, as a result of annealing and subsequent water cooling, the eutectic regions transformed to grains of the $\mathrm{Zn}_{11} \mathrm{Mg}_{2}$ phase enriched in Ag with a morphology similar to the grains reported earlier for the $\mathrm{Zn}-0.5 \mathrm{Mg}$ alloy. ${ }^{[10]}$ Interestingly, a large number of nanometric particles of the $\mathrm{Zn}_{2} \mathrm{Mg}$ phase precipitated after plastic deformation. This is consistent with the results for a $\mathrm{Zn}-1.6 \mathrm{Mg}$ alloy where precipitates of the $\mathrm{Zn}_{2} \mathrm{Mg}$ phase also formed in the larger $\mathrm{Zn}_{11} \mathrm{Mg}_{2}$ grains after a hot ECAP process. ${ }^{[23]}$

Precipitation of the $\varepsilon-\mathrm{Zn}_{3} \mathrm{Ag}$ phase occurred either during $\mathrm{HE}$ or in the cooling after processing due to the limited solubility of $\mathrm{Ag}$ in $\mathrm{Zn}$ at $250{ }^{\circ} \mathrm{C}$. It appears that in the sample after CR the phase composition remains the same. The precipitation of the $\mathrm{Zn}_{2} \mathrm{Mg}$ and $\varepsilon-\mathrm{Zn}_{3} \mathrm{Ag}$ phases may occur as larger plastic strains are applied during HPT processing. According to the STEM-EDS analysis, the $\mathrm{Mg}$-rich phases are enriched in $\mathrm{Ag}$ and the similar atomic radii of $\mathrm{Ag}(144 \mathrm{pm})$ and $\mathrm{Mg}(145 \mathrm{pm})$ suggests that $\mathrm{Ag}$ can substitute $\mathrm{Mg}$ in these phases.

\section{B. Effect of Microstructure and Grain Size on Mechanical Behavior}

In polycrystalline HCP materials, deformation begins by slip and, due to insufficient strain accommodation, the slip is accompanied by twinning. The grain size plays a vital role in the activation of twinning. Thus, it was shown that the critical stress for twinning in $\mathrm{Zn}$ alloys increases with a decrease in grain size, and the contribution of twinning to the total deformation increases with increasing grain size. ${ }^{[48]}$ As documented for pure $\mathrm{Mg},{ }^{[49]}$ a decrease in grain size below a critical value of $\sim 2.7 \mu \mathrm{m}$ inhibits twinning and promotes dislocation slip and other deformation mechanisms. The twinning occurring in coarse-grained HCP metals contributes to higher strengthening and lower plasticity than in fine-grained metals and this is consistent with the present results for the HE alloy where this sample exhibits the highest YS for all strain rates. The decrease in YS caused by microstructure refinement in the CR and HPT samples suggests the advent of other mechanisms such as grain boundary sliding (GBS).

It is well known that the size, morphology, and distribution of microstructural features play a significant role in determining the strength and ductility. Typically, hard precipitates located at grain boundaries do not produce reasonable plasticity. ${ }^{[5]}$ However, despite the apparent brittleness of the HE samples, in the CR and HPT states the Mg- and Ag-rich precipitates have similar sizes and morphology but exhibit increased ductility which is probably due to the occurrence of GBS. This flow mechanism will affect the accommodation of external stresses and thereby produce additional deformation instead of brittle fracture. ${ }^{[14]}$ As a result, high-stress zones are formed around the intermetallic precipitates and these will hinder grain movement and act as nucleation sites for new dynamically recrystallized grains, as was observed in a $\mathrm{Zn}-3 \mathrm{Cu}-\mathrm{xFe}$ alloy. ${ }^{[1]}$ 

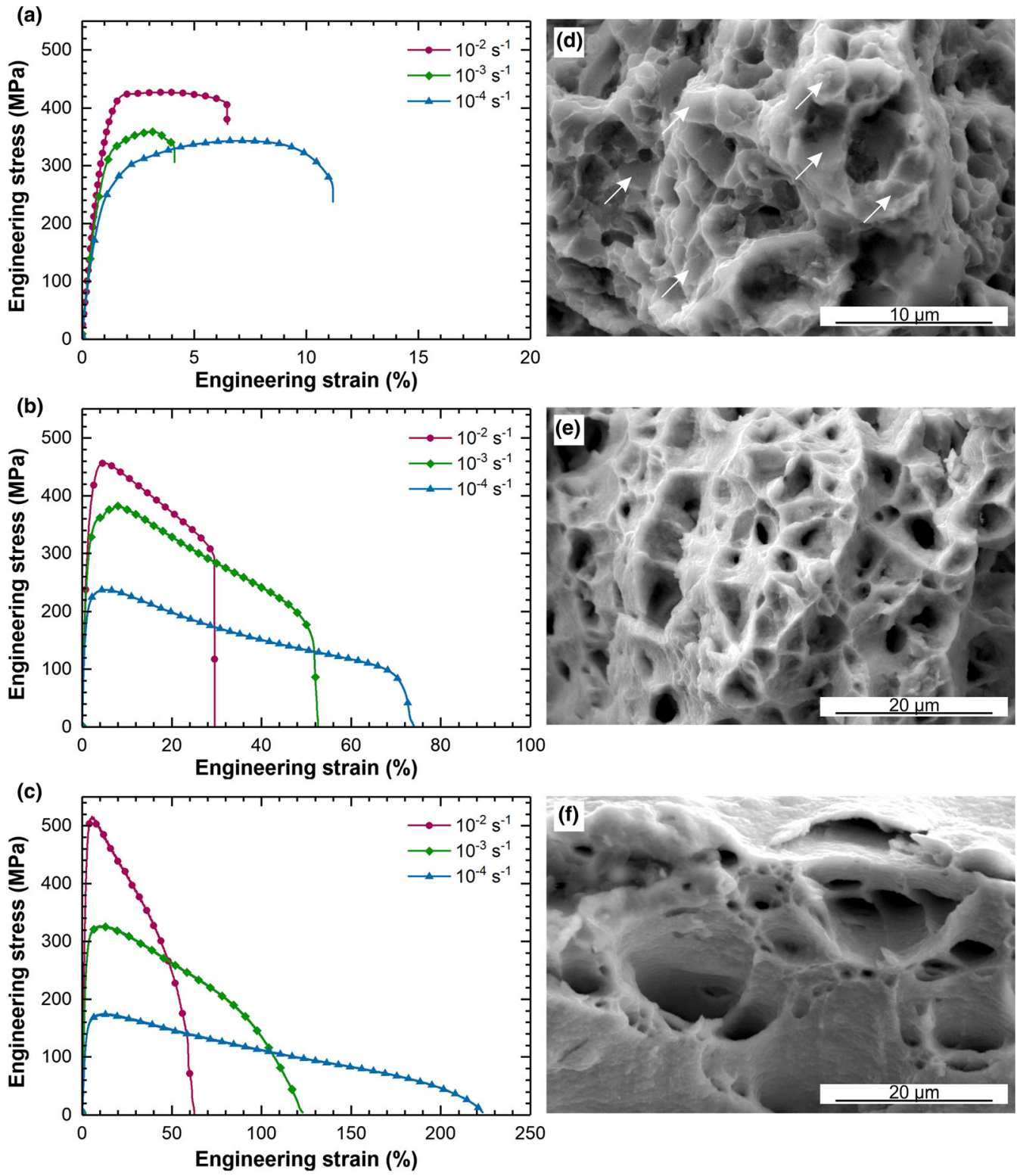

Fig. 8-Engineering strain-stress curves of $\mathrm{Zn}-3 \mathrm{Ag}-0.5 \mathrm{Mg}$ alloy and fracture morphologies investigated after tensile test conducted at $10^{-3} \mathrm{~s}^{-1}$ for HE $((a),(d))$, CR $((b),(e))$, and HPT $((c),(f))$ samples. Please pay attention to different scale bars in figures (d) to (f) and different elongation ranges on the $x$-axis.

\section{Effect of Strain Rate on Mechanical Properties}

Zinc is characterized by a low melting temperature and therefore deformation of samples processed at RT may be analyzed using mechanisms associated with elevated temperature tensile testing. Thus, the steadystate strain rate, $\dot{\varepsilon}$, may be expressed by the relationship:

$$
\dot{\varepsilon}=\frac{A D G b}{k T}\left(\frac{b}{d}\right)^{p}\left(\frac{\sigma}{G}\right)^{n^{\prime}}
$$

where $A$ is a dimensionless constant, $D$ is the appropriate diffusion coefficient, $G$ is the shear modulus, $b$ is the Burgers vector, $k$ is Boltzmann's constant, $T$ is the absolute temperature, $d$ is the grain size, $\sigma$ is the applied stress, $p$ is the inverse grain size exponent, and $n^{\prime}$ is the stress exponent which is equal to the inverse of the strain rate sensitivity, $m$.

Based on the UTS in Table III, the values of $m$ were calculated for the strain rate ranges of $10^{-2}-10^{-3} \mathrm{~s}^{-1}$ and $10^{-3}-10^{-4} \mathrm{~s}^{-1}$ and the results are presented in Figure 9(a). Similarly, the variation of the elongation to failure with strain rate is shown in Figure 9(b). The elongations recorded in this investigation reached a maximum of 220 pct in the HPT sample at a strain rate of $10^{-4} \mathrm{~s}^{-1}$ and the associated strain rate sensitivity was $m \approx 0.27$. Thus, these results fail to fulfill the requirements for superplasticity where, by definition, the elongations must be at least as high as 400 pct with a 
Table III. Mechanical Properties of Zn-3Ag-0.5Mg Alloy After HE, CR, and HPT with the Measurement Uncertainty Values

\begin{tabular}{|c|c|c|c|c|c|c|c|c|c|}
\hline \multirow[b]{2}{*}{ Strain rate $\left(\mathrm{s}^{-1}\right)$} & \multicolumn{3}{|c|}{ YS (MPa) } & \multicolumn{3}{|c|}{ UTS (MPa) } & \multicolumn{3}{|c|}{ Elongation (Pct) } \\
\hline & $10^{-2}$ & $10^{-3}$ & $10^{-4}$ & $10^{-2}$ & $10^{-3}$ & $10^{-4}$ & $10^{-2}$ & $10^{-3}$ & $10^{-4}$ \\
\hline $\mathrm{HE}$ & $362 \pm 3$ & $283 \pm 3$ & $229 \pm 2$ & $427 \pm 4$ & $359 \pm 4$ & $343 \pm 3$ & $6.5 \pm 0.8$ & $4.1 \pm 0.7$ & $11.2 \pm 0.8$ \\
\hline CR & $321 \pm 4$ & $254 \pm 4$ & $168 \pm 2$ & $456 \pm 6$ & $382 \pm 5$ & $238 \pm 3$ & $30 \pm 1$ & $53 \pm 1$ & $73 \pm 1$ \\
\hline HPT & $359 \pm 12$ & $214 \pm 7$ & $113 \pm 4$ & $516 \pm 13$ & $327 \pm 8$ & $175 \pm 5$ & $62 \pm 2$ & $122 \pm 2$ & $224 \pm 6$ \\
\hline
\end{tabular}

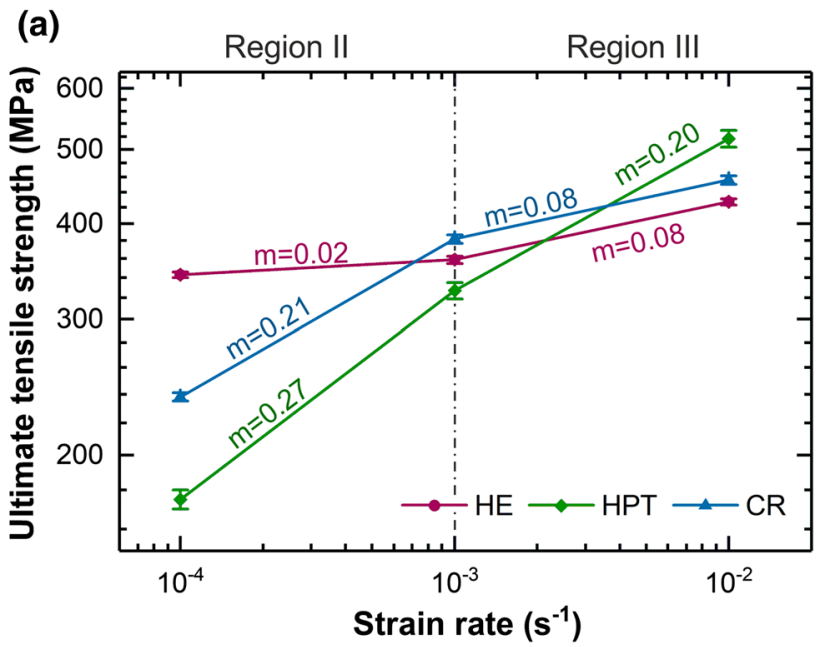

(b)

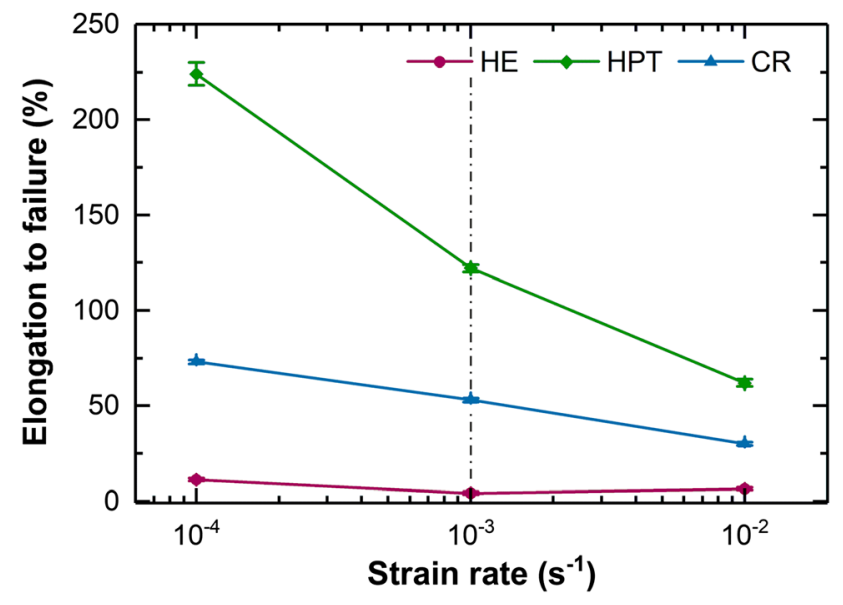

Fig. 9-Variation of the ultimate tensile strength $(a)$ and elongation (b) $v s$ strain rate.

value of $m \approx 0.5 .^{[52]}$ The limited elongation and the value of $m$ close to $\sim 0.3$ obtained for the HPT sample are consistent instead with dislocation glide as the rate-controlling flow process. ${ }^{[53]}$ By contrast, there are some earlier reports documenting true superplastic flow in tensile testing at RT in some ultrafine-grained $\mathrm{Zn}$ alloys obtained by SPD processing: for example, elongations of 510 pct in a $\mathrm{Zn}-0.5 \mathrm{Cu}$ alloy, ${ }^{[54]} 520$ pct in a $\mathrm{Zn}-5 \mathrm{Al}$ alloy, ${ }^{55]}$ and up to $1000 \mathrm{pct}$ in a $\mathrm{Zn}-0.3 \mathrm{Al}$ alloy. ${ }^{[56]}$

\section{Implications of These Results for the Production of Cardiovascular Stents}

High flow stress, low yield stress, and therefore high strain hardening ability are desirable when considering materials for stent production. Together with the appropriate ductility, it provides an adequate plastic deformation range within which the stent can be radially expanded inside the vessel, thereby avoiding localized strain concentrations or premature fractures. This is mainly associated with developing resistance to dislocation slip by twin boundaries, high-angle grain boundaries and second-phase particles. ${ }^{[57]}$ The strain hardening exponent, $n$, was estimated from double logarithmic true stress-true strain curves (not presented here) within the uniform plastic deformation ranges for the HE, CR, and HPT samples.

The general observation made for samples after the three deformation methods was that the strain hardening exponent was high at the low strains and then decreased at higher strains. This behavior was observed for all tested strain rates and the changes of $n$ between low strain ranges and high strain ranges were most significant, while differences between different strain rates and different materials were much less pronounced. The changes of $n$ with strain variation were previously observed in various metals and alloys and the character of these changes was described as being dependent on phase composition and the presence of structural or phase transformations during the deformation. ${ }^{[58]}$ The increased strain hardening exponent in the low strain range was observed in martensitic steels due to $\mathrm{Ni}_{3} \mathrm{Al}$ precipitation, followed by decreased $n$ at high strains. ${ }^{[59]}$ Similarly, in the currently investigated $\mathrm{Zn}-3 \mathrm{Ag}-0.5 \mathrm{Mg}$ the initial high $n$ value can be explained by dislocation interactions with dispersed $\mathrm{Zn}_{3} \mathrm{Ag}$ and $\mathrm{Zn}_{11} \mathrm{Mg}_{2} / \mathrm{Zn}_{2} \mathrm{Mg}$ precipitates (Figure 5). After the initial hardening, the generation rate of new dislocations and the dislocation-precipitate interaction number reaches equilibrium, resulting in a decreased strain hardening exponent. At higher strains in zinc alloys, the dislocation density can be controlled by a relatively high rate of dynamic recovery due to the high homologous temperature of deformation. In addition, as the material is hardened, at higher strains different deformation mechanisms such as GBS become more important resulting in decreased hardening ability and increased plasticity.

For the HE samples, the initial strain hardening exponent $n$ was similar at all strain rates and equaled about 0.3. Further straining led to a change of $n$ to lower 
values, below 0.16 , but within a narrow deformation range before the brittle fracture. For comparison, the $\mathrm{Zn}-0.5 \mathrm{Mg}$ extruded alloy with a grain size of $4.1 \mu \mathrm{m}$ tested at $10^{-3} \mathrm{~s}^{-1}$ exhibits a strain hardening exponent equal to 0.22 within the whole uniform plastic deformation range. ${ }^{[10]}$ The higher $n$ value obtained in the same conditions for the $\mathrm{Zn}-3 \mathrm{Ag}-0.5 \mathrm{Mg}$ alloy can result from the presence of dispersed precipitates, whereas in the microstructure of the $\mathrm{Zn}-0.5 \mathrm{Mg}$ alloy there are $\mathrm{Zn}_{11} \mathrm{Mg}_{2}$ particles which are located mostly at grain boundaries. The additional strain hardening effect in the $\mathrm{Zn}-3 \mathrm{Ag}-0.5 \mathrm{Mg}$ alloy can result from $\mathrm{Ag}$ solid solubility in the $\mathrm{Zn}$ matrix. On the other hand, the analyzed strain hardening behavior stands in contrast to the results shown for quasi-single-phase extruded $\mathrm{Zn}-0.8 \mathrm{Ag}$ alloy with a grain size of $50.3 \mu \mathrm{m}$, where increasing strain caused the increase in the strain hardening exponent from 0.07 to 0.22 . $^{[14]}$ That observation was explained by the twinning deformation in the first stage resulting in decreased initial strain hardening, followed by an increase of $n$ due to strong dislocation-twin interactions in the second stage. In the current study, twinning is still possible in coarse grains; however, the much lower average grain size $(6.0 \pm 2.5 \mu \mathrm{m})$ decreases the ability of twinning to act as a primary strain accommodation mechanism and removes the possibility of decreased $n$ at the onset of deformation. By contrast, the presence of second-phase precipitates and solid solution strengthening due to higher Ag content in the $\mathrm{Zn}-3 \mathrm{Ag}-0.5 \mathrm{Mg}$ alloy leads to a stronger strain hardening in the first stage of deformation.

In the CR samples, at the first stage, strain hardening occurred with $n$ having values from 0.29 to 0.39 at $10^{-4}$ $\mathrm{s}^{-1}$ and $10^{-2} \mathrm{~s}^{-1}$, respectively. Similarly to $\mathrm{HE}$, this is generally associated with an increase in the dislocation density during deformation and dislocation-precipitate interactions. At higher strains, $n$ decreases to values between 0.15 and 0.09 with decreasing strain rate. As presented in Figure 6(b), the microstructure of the $\mathrm{Zn}-3 \mathrm{Ag}-0.5 \mathrm{Mg}$ alloy after CR consists of grains with a wider size distribution, and the overall distribution is shifted towards a more refined microstructure. A smaller grain size and higher grain boundary density allow the GBS to contribute much more to the overall deformation behavior, resulting in increased plasticity and a decreased hardening exponent especially at lower strain rates.

The samples after HPT processing exhibit the largest strain hardening exponent in the low strain range in comparison to the $\mathrm{HE}$ and $\mathrm{CR}$ samples. Initially, the $n$ exponent reaches 0.50 at $10^{-2} \mathrm{~s}^{-1}$ and about 0.46 at lower strain rates and then decreases to about 0.11 in the high strain region. High $n$ values are associated with a strong basal texture (Figure 7(c)) and the large fraction of HAGB with misorientation angles below $30 \mathrm{deg}$ (Figure 7(f)). In this case, a relatively sharp basal texture results in a quicker dislocation pile-up and thus a higher strain hardening exponent in the initial deformation stage. Further straining leads to an increase in dislocation density, possibly followed by dynamic recrystallization which can introduce changes in grain boundary structures and increase of the average boundary misorientation angle. Consequently, the ultrafine-grained HPT specimens at higher strains became more prone to GBS because of the higher fraction of high-energy grain boundaries providing very high plasticity. ${ }^{[60]}$ Similar results were also reported for ultrafine-grained pure $\mathrm{Zn},{ }^{[61]} \mathrm{Zn}-0.5 \mathrm{Cu},{ }^{[62]}$ and the $\mathrm{Zn}-22 \mathrm{Al}$ eutectoid alloy ${ }^{[63]}$ after processing by HPT.

As mentioned earlier, it is crucial for a material under consideration for stent production to exhibit a strain hardening ability within the required range of deformation. In the CR and HPT samples, the hardenability was recorded in a significantly wider strain range than in the $\mathrm{HE}$ samples where this is mostly related to the smaller grain sizes and higher densities of grain boundaries. Ideally, the transition from strain hardening to strain softening should be avoided, and based on results presented for the $\mathrm{Zn}-1 \mathrm{Cu}^{[64]}$ and $\mathrm{Zn}-4 \mathrm{Ag}-0.6 \mathrm{Mn}^{[65]}$ alloys this may be addressed by additional heat treatment after cold deformation processes. In fact, the observed differences in strain hardening exponent $n$ between the tested specimens may be affected by several factors such as grain size, strain level (as discussed above), strain rate, texture, and grain boundary character distribution.

An appraisal of all data obtained from this investigation shows that processing by $\mathrm{HE}, \mathrm{CR}$, and HPT provide materials that have reasonable properties for the production of biomedical stents. Nevertheless, it appears that the ductile CR samples are especially attractive for meeting the requirements for use in cardiovascular applications. Thus, the average grain size is $\sim 2 \mu \mathrm{m}$, and there is a favorable rolling texture, a YS of $\sim 254 \mathrm{MPa}$ at a strain rate of $10^{-3} \mathrm{~s}^{-1}$, a corresponding UTS close to $\sim 400 \mathrm{MPa}$, and reasonable values for the strain rate sensitivity and strain hardening exponent.

\section{SUMMARY AND CONCLUSIONS}

1. This work focused on processing a high-strength ductile $\mathrm{Zn}-3 \mathrm{Ag}-0.5 \mathrm{Mg}$ alloy via hot, cold, and severe plastic deformation techniques and identifying the factors influencing the flow properties.

2. A high strength but relatively brittle $\mathrm{Zn}$ alloy was obtained by hot extrusion. The additional application of cold rolling after $\mathrm{HE}$ gave a significantly enhanced ductility and a negligible decrease in the yield and flow stress. Processing by HPT gave a very high strength and excellent elongations to failure but with a relatively high strain rate sensitivity.

3. The optimum processing condition for the production of cardiovascular stents appears to be cold rolling after HE where there is a reasonable yield stress and ultimate tensile stress, and good values for the strain rate sensitivity and strain hardening exponent. The results appear to satisfy the listed requirements for short-term biomedical implants but further research will be needed to evaluate the biodegradation behavior and relevant biological aspects. 


\section{ACKNOWLEDGMENTS}

This work was supported by the Polish National Science Centre [Grant Number 2018/29/N/ST8/01703]. The authors thank Dr. Marianna Marciszko for the assistance during the XRD measurements and Krzysztof Maćkosz for the preparation of thin lamellae for TEM observations, both from AGH University of Science and Technology in Cracow, Poland.

\section{OPEN ACCESS}

This article is licensed under a Creative Commons Attribution 4.0 International License, which permits use, sharing, adaptation, distribution and reproduction in any medium or format, as long as you give appropriate credit to the original author(s) and the source, provide a link to the Creative Commons licence, and indicate if changes were made. The images or other third party material in this article are included in the article's Creative Commons licence, unless indicated otherwise in a credit line to the material. If material is not included in the article's Creative Commons licence and your intended use is not permitted by statutory regulation or exceeds the permitted use, you will need to obtain permission directly from the copyright holder. To view a copy of this licence, visit http://creat ivecommons.org/licenses/by/4.0/.

\section{REFERENCES}

1. G. Li, H. Yang, Y. Zheng, X.-H. Chen, J.-A. Yang, D. Zhu, L. Ruan, and K. Takashima: Acta Biomater., 2019, vol. 97, pp. 23-45.

2. P.K. Bowen, J. Drelich, and J. Goldman: Adv. Mater., 2013, vol. 25 , pp. $2577-82$

3. J.C.T. Farge: McGill University Montreal, Canada, 1999.

4. J. Li, W. Xu, X. Wu, H. Ding, and K. Xia: Mater. Sci. Eng. A, 2011, vol. 528, pp. 5993-8.

5. E.O. Hall: Proc. Phys. Soc. Sect. B, 1951, vol. 64, pp. 747-53.

6. N. Balasubramanian and T.G. Langdon: Metall. Mater. Trans. A, 2016, vol. 47A, pp. 5827-38.

7. M. Wątroba, W. Bednarczyk, J. Kawałko, and P. Bała: Mater. Charact., 2018, vol. 142, pp. 187-94.

8. M. Sikora-Jasinska, E. Mostaed, A. Mostaed, R. Beanland, D. Mantovani, and M. Vedani: Mater. Sci. Eng. C, 2017, vol. 77, pp. $1170-81$.

9. Z. Tang, J. Niu, H. Huang, H. Zhang, J. Pei, J. Ou, and G. Yuan: J. Mech. Behav. Biomed. Mater., 2017, vol. 72, pp. 182-91.

10. E. Mostaed, M. Sikora-Jasinska, A. Mostaed, S. Loffredo, A.G. Demir, B. Previtali, D. Mantovani, R. Beanland, and M. Vedani: J. Mech. Behav. Biomed. Mater., 2016, vol. 60, pp. 581-602.

11. N. Hansen: Scr. Mater., 2004, vol. 51, pp. 801-06.

12. S. Thangaraju, M. Heilmaier, B.S. Murty, and S.S. Vadlamani: Adv. Eng. Mater., 2012, vol. 14, pp. 892-97.

13. Z. Liu, F. Wang, D. Qiu, J.A. Taylor, and M. Zhang: Metall. Mater. Trans. A, 2013, vol. 44A, pp. 4025-30.

14. W. Bednarczyk, M. Wątroba, J. Kawałko, and P. Bała: Mater. Sci. Eng. A, 2019, vol. 748, pp. 357-66.

15. L. Sun, J. Bai, F. Xue, L. Tao, C. Chu, and J. Meng: Mater. Des., 2017, vol. 135, pp. 267-74.

16. M. Watroba, W. Bednarczyk, J. Kawałko, K. Mech, M. Marciszko, G. Boelter, M. Banzhaf, and P. Bała: Mater. Des., 2019, vol. 183, p. 108154

17. J. Venezuela and M.S. Dargusch: Acta Biomater., 2019, vol. 87, pp. $1-40$.
18. Y. Qin, P. Wen, H. Guo, D. Xia, Y. Zheng, L. Jauer, R. Poprawe, M. Voshage, and J.H. Schleifenbaum: Acta Biomater., 2019, vol. 98 , pp. 3-22.

19. S. Zhao, C.T. McNamara, P.K. Bowen, N. Verhun, J.P. Braykovich, J. Goldman, and J.W. Drelich: Metall. Mater. Trans. A, 2017, vol. 48A, pp. 1204-15.

20. Y. Zhang, Y. Yan, X. Xu, Y. Lu, L. Chen, D. Li, Y. Dai, Y. Kang, and K. Yu: Mater. Sci. Eng. C, 2019, vol. 99, pp. 1021-34.

21. Z. Tang, H. Huang, J. Niu, L. Zhang, H. Zhang, J. Pei, J. Tan, and G. Yuan: Mater. Des., 2017, vol. 117, pp. 84-94.

22. C. Shen, X. Liu, B. Fan, P. Lan, F. Zhou, X. Li, H. Wang, X. Xiao, L. Li, S. Zhao, Z. Guo, Z. Pu, and Y. Zheng: RSC Adv., 2016, vol. 6, pp. 86410-19.

23. H. Liu, H. Huang, Y. Zhang, Y. Xu, C. Wang, J. Sun, J. Jiang, A. Ma, F. Xue, and J. Bai: J. Alloys Compd., 2019, vol. 811, p. 151987.

24. L. Wang, Y. He, H. Zhao, H. Xie, S. Li, Y. Ren, and G. Qin: $J$. Alloys Compd., 2018, vol. 740, pp. 949-57.

25. H. Jin, S. Zhao, R. Guillory, P.K. Bowen, Z. Yin, A. Griebel, J. Scha, E.J. Earley, J. Goldman, and J.W. Drelich: Mater. Sci. Eng. C, 2018, vol. 84, pp. 67-79.

26. A. Jarzębska, M. Bieda, J. Kawałko, Ł. Rogal, P. Koprowski, K. Sztwiertnia, W. Pachla, and M. Kulczyk: Mater. Lett., 2018, vol. 211, pp. 58-61.

27. M.S. Ardakani, E. Mostaed, M. Sikora-Jasinska, S.L. Kampe, and J.W. Drelich: Mater. Sci. Eng. A, 2020, vol. 770, p. 138529.

28. P. Li, W. Zhang, J. Dai, A.B. Xepapadeas, E. Schweizer, D. Alexander, L. Scheideler, C. Zhou, H. Zhang, G. Wan, and J. Geis-Gerstorfer: Mater. Sci. Eng. C, 2019, vol. 103, p. 109826.

29. Z. Li, Z.-Z. Shi, Y. Hao, H.-F. Li, X.-F. Liu, A.A. Volinsky, H.-J. Zhang, and L.-N. Wang: J. Mater. Sci. Technol., 2019, vol. 35 , pp. $2618-24$.

30. W. Bednarczyk, M. Wątroba, J. Kawałko, and P. Bała: Mater. Sci. Eng. A, 2019, vol. 759, pp. 55-58.

31. P. Kumar, C. Xu, and T.G. Langdon: Mater. Sci. Eng. A, 2006, vol. 429 , pp. 324-28.

32. B. Srinivasarao, A.P. Zhilyaev, T.G. Langdon, and M.T. Pérez-Prado: Mater. Sci. Eng. A, 2013, vol. 562, pp. 196-202.

33. R.B. Figueiredo, P.R. Cetlin, and T.G. Langdon: Mater. Sci. Eng. A, 2011, vol. 528, pp. 8198-204.

34. A.A. Coelho: Bruker AXS GmbH, Karlsruhe, Germany.

35. H.M. Rietveld: J. Appl. Crystallogr., 1969, vol. 2, pp. 65-71.

36. W. Gabauer: The Determination of Uncertainties in Tensile Testing. Manual of Codes of Practice for the Determination of Uncertainties in Mechanical Tests on Metallic Materials, 2000.

37. H. Baker, ed.: ASM Handbook: Alloy Phase Diagrams. Volume 3, ASM International, New York, 1998.

38. M.H. Yoo: Metall. Trans. A, 1981, vol. 12, pp. 409-18.

39. T. Gómez-Acebo: CALPHAD, 1998, vol. 22, pp. 203-20.

40. R.Z. Valiev, Y. Estrin, Z. Horita, T.G. Langdon, M.J. Zehetbauer, and Y. Zhu: JOM, 2016, vol. 68, pp. 1216-26.

41. S. Kleiner and P.J. Uggowitzer: Mater. Sci. Eng. A, 2004, vol. 379, pp. 258-63.

42. D.E. Solas, C.N. Tomé, O. Engler, and H.R. Wenk: Acta Mater., 2001, vol. 49, pp. 3791-801.

43. Y.N. Wang and J.C. Huang: Mater. Chem. Phys., 2003, vol. 81, pp. $11-26$

44. D. Hernández-Escobar, Z.U. Rahman, H. Yilmazer, M. Kawasaki, and C.J. Boehlert: Philos. Mag., 2019, vol. 99, pp. 557-84.

45. S. Suwas and R.K. Ray: Crystallographic Texture of Materials, vol. 46, 1st edn., Springer, London, 2014.

46. T.A. Vida, A. Conde, E.S. Freitas, M.A. Arenas, N. Cheung, C. Brito, J. de Damborenea, and A. Garcia: J. Alloys Compd., 2017, vol. 723 , pp. $536-47$

47. L. Li, R. Zhang, C. Ban, H. Zhang, T. Liu, H. Zhang, X. Wang, C. Esling, and J. Cui: Mater. Charact., 2019, vol. 151, pp. 191-202.

48. N. Ecob and B. Ralph: J. Mater. Sci., 1983, vol. 18, pp. 2419-29.

49. H. Fan, S. Aubry, A. Arsenlis, and J.A. El-Awady: Scr. Mater., 2016, vol. 112 , pp. $50-53$.

50. J. Kubásek, D. Vojtěch, E. Jablonská, I. Pospíšilová, J. Lipov, and T. Ruml: Mater. Sci. Eng. C, 2016, vol. 58, pp. 24-35.

51. R. Yue, H. Huang, G. Ke, H. Zhang, J. Pei, G. Xue, and G. Yuan: Mater. Charact., 2017, vol. 134, pp. 114-22.

52. T.G. Langdon: J. Mater. Sci., 2009, vol. 44, pp. 5998-6010. 
53. T.G. Langdon: Zeitschrift für Met., 2005, vol. 96, pp. 522-31.

54. W. Bednarczyk, J. Kawałko, M. Wątroba, and P. Bała: Mater. Sci. Eng. A, 2018, vol. 723, pp. 126-33.

55. M. Demirtas, G. Purcek, H. Yanar, Z.J. Zhang, and Z.F. Zhang: J. Alloys Compd., 2015, vol. 623, pp. 213-18.

56. M. Demirtas, G. Purcek, H. Yanar, Z.J. Zhang, and Z.F. Zhang: Mater. Sci. Eng. A, 2015, vol. 644, pp. 17-24.

57. J. Jiang, G. Bi, G. Wang, Q. Jiang, J. Lian, and Z. Jiang: J. Magnes. Alloy., 2014, vol. 2, pp. 116-23.

58. V.A. Krokha: Strength Mater., 1981, vol. 13, pp. 1022-27.

59. J.-H. Shin, J. Jeong, and J.-W. Lee: Mater. Charact., 2015, vol. 99, pp. $230-37$.

60. T. Watanabe: Mater. Sci. Forum, 1996, vols. 243-245, pp. 21-30.

61. K. Edalati and Z. Horita: Mater. Sci. Eng. A, 2011, vol. 528, pp. 7514-23.
62. W. Bednarczyk, J. Kawałko, M. Wątroba, N. Gao, M.J. Starink, P. Bała, and T.G. Langdon: Mater. Sci. Eng. A, 2020, vol. 776, p. 139047.

63. T.-S. Cho, H.-J. Lee, B. Ahn, M. Kawasaki, and T.G. Langdon: Acta Mater., 2014, vol. 72, pp. 67-79.

64. E. Mostaed, M.S. Ardakani, M. Sikora-Jasinska, and J.W. Drelich: Mater. Lett., 2019, vol. 244, pp. 203-06.

65. E. Mostaed, M. Sikora-Jasinska, M.S. Ardakani, A. Mostaed, I.M. Reaney, J. Goldman, and J.W. Drelich: Acta Biomater., 2020, vol. 105, pp. 319-35.

Publisher's Note Springer Nature remains neutral with regard to jurisdictional claims in published maps and institutional affiliations. 